\title{
Infectious endophthalmitis at a Philippine tertiary hospital: a ten-year retrospective study
}

Victoria Grace Dimacali ${ }^{*}$ and Ruben Lim Bon Siong

\begin{abstract}
Background: Endophthalmitis is a sight-threatening disease characterized by marked progressive inflammation of the vitreous and/or aqueous humors. Limited information is currently available regarding endophthalmitis in the Philippines. This study aimed to provide long-term summary data on endophthalmitis cases seen at the largest tertiary referral hospital in the Philippines.

Methods: All endophthalmitis cases diagnosed at the Philippine General Hospital from January 1, 2007 to December 31, 2016 were retrieved and classified by etiology. Data pertaining to history, associated risk factors, isolated microorganisms, management, and final visual outcomes for each patient were reviewed.

Results: A total of 202 cases diagnosed within the audit period were included in the study. These were classified as post-traumatic (55.94\%), endogenous (14.36\%), acute post-operative (10.40\%), keratitis-induced (6.93\%), chronic post-operative (5.44\%), bleb-associated (3.96\%), and suture-associated (2.97\%) endophthalmitis. Males comprised $71.29 \%$ of the population, while the largest age group affected was $0-10$ years (24.75\%). The culture-positive rate was 57.89\%. The predominant etiology was Gram-positive bacteria (38.18\%), followed by Gram-negative bacteria and mixed pathogens (21.82\% each), and fungi (18.18\%). The most common organisms were Streptococcus, Staphylococcus, Pseudomonas, Aspergillus, and Candida, accounting for $56.45 \%$ of isolates. Pars plana vitrectomy was done for $62.87 \%$ of patients, intravitreal and other antibiotic therapy in $23.27 \%$, and primary enucleation/ evisceration in $10.89 \%$. The final outcomes and best corrected visual acuities were: anophthalmia $11.86 \%$, no light perception/no dazzle $27.84 \%$, light perception $8.76 \%$, hand motions $24.23 \%$, counting fingers $5.15 \%, 3 / 200$ to $20 / 50$ $12.89 \%$, and $20 / 40$ to $20 / 209.28 \%$.

\footnotetext{
* Correspondence: victoriagrace.dimacali@gmail.com

Department of Ophthalmology and Visual Sciences, College of

Medicine-Philippine General Hospital, University of the Philippines Manila,

Manila, Philippines
}

\section{Springer Open}

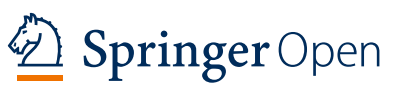

(c) The Author(s). 2020 Open Access This article is licensed under a Creative Commons Attribution 4.0 International License, which permits use, sharing, adaptation, distribution and reproduction in any medium or format, as long as you give appropriate credit to the original author(s) and the source, provide a link to the Creative Commons licence, and indicate if changes were made. The images or other third party material in this article are included in the article's Creative Commons licence, unless indicated otherwise in a credit line to the material. If material is not included in the article's Creative Commons licence and your intended use is not permitted by statutory regulation or exceeds the permitted use, you will need to obtain permission directly from the copyright holder. To view a copy of this licence, visit http://creativecommons.org/licenses/by/4.0/. 


\begin{abstract}
(Continued from previous page)
Conclusions: There was a higher proportion of post-traumatic endophthalmitis cases compared to traditional estimates but consistent with studies from China and Thailand. The majority of these cases involved younger children as well as young to middle-aged males engaged in carpentry and construction work, implying a need for increased public health awareness and strengthening of childcare and workplace safety policies. Our microbiologic profile showed a lower proportion of Gram-positive infections and a higher proportion of mixed pathogen infections compared to other studies. There was also a higher proportion of fungi associated with post-operative and keratitis-induced endophthalmitis. The best outcomes were seen in acute post-operative and bleb-associated endophthalmitis, and the worst outcomes in endogenous and keratitis-induced endophthalmitis. Visual outcomes were poorer compared to other Western and Asian countries, with only $21.7 \%$ of patients improving from presentation.
\end{abstract}

Keywords: Endophthalmitis, Infection, Trauma, Exogenous, Endogenous, Post-operative, Keratitis, Bleb, Suture

\section{Introduction}

Endophthalmitis is a rare but sight-threatening disease characterized by marked progressive inflammation of the vitreous and/or aqueous humors, usually due to an intraocular bacterial, fungal, parasitic or rarely, viral infection [1-3]. It is traditionally classified according to etiology as post-operative, post-traumatic, endogenous, or keratitis-induced. Other ways of classification are by the organism(s) involved and by the clinical course (acute or chronic/delayed-onset) [2].

In many developed countries, post-operative cases make up the majority of endophthalmitis [4]. Acuteonset post-operative endophthalmitis is defined as occurring within six weeks of ocular surgery, while chronic or delayed-onset occurs past this period. Most patients with the acute-onset type present within seven days. Cataract surgeries, one of the most common eye operations performed worldwide, are responsible for the majority of acute cases with reported incidences ranging from $0.03 \%$ to $0.2 \%$ [1]. Chronic post-operative endophthalmitis occurring after cataract surgery is less common, with one study reporting an incidence of $0.02 \%$ [5]. Another review showed that it only accounted for $7.2 \%$ of cultureproven post-operative endophthalmitis cases [6]. Chronic post-operative endophthalmitis progresses slowly and may present with only mild inflammation [1].

Bleb-associated and suture-related endophthalmitis can also be classified as post-operative endophthalmitis. Bleb-associated endophthalmitis is usually seen in the late (more than 4 weeks) post-surgical period following a trabeculectomy, but may also present acutely. The time from surgery to presentation can range from 1.5 to 7 years. Incidences from $0.17 \%$ to $13.2 \%$ have been reported [1]. The risk of endophthalmitis is estimated to be $1.3 \%$ per patient-year [3]. Blebitis should also be ruled out in these cases [1].

Relatively few cases of corneal suture-related endophthalmitis have been reported in the literature. One retrospective consecutive case series showed only six endophthalmitis cases associated with culture-proven corneal suture infections within a 15-year period [7].

Post-traumatic endophthalmitis is a significant complication that can follow penetrating eye trauma. Incidences from $0 \%$ to $12 \%$ have been reported, increasing to as much as $60 \%$ in the presence of an intraocular foreign body (IOFB) [1, 2]. Early surgical repair and prophylactic systemic antibiotics may reduce this incidence to $<1 \%$ [3]. It is estimated that around $25 \%$ of endophthalmitis cases are due to ocular trauma [8].

Endogenous endophthalmitis is uncommon, representing an estimated $2 \%$ to $16 \%$ of all reported endophthalmitis cases [1]. The majority of patients are adults, with pediatric cases accounting for only $0.1 \%$ to $4 \%$ [2]. There may either be evident systemic sepsis, or a multiorgan subclinical or localized infection. In the latter, transient bacteremia or fungemia may explain the spread of the pathogen to the eye [2].

Infectious keratitis does not usually progress to endophthalmitis. A large retrospective study showed that only $0.5 \%$ of eyes with suspected infectious keratitis advanced to culture-proven endophthalmitis [9]. However, it is usually difficult to distinguish keratitis from endophthalmitis because they both present with pain, significant visual loss, hypopyon, and poor view of the posterior segment.

To the authors' knowledge, there has only been one local study on endophthalmitis to date. De Sagun-Bella and Santos analyzed 114 endophthalmitis cases seen from 2005 to 2015 by the Surgical Retina service of the Department of Ophthalmology and Visual Sciences of the Philippine General Hospital (DOVS-PGH), the largest tertiary referral hospital in the Philippines [10]. They reported that post-traumatic cases were the most common type (64.9\%), followed by post-surgical (24.5\%) and endogenous cases (10.5\%). Management was as follows: $81.5 \%$ underwent pars plana vitrectomy (PPV), $11.4 \%$ were enucleated, and $7.0 \%$ of eyes were managed 
Table 1 Classification and demographic data of endophthalmitis cases $(n=202)$. Post-traumatic cases made up more than half of the population, and were associated with younger age and a higher male to female ratio

\begin{tabular}{|c|c|c|c|c|c|}
\hline \multirow{2}{*}{$\begin{array}{l}\text { Type of } \\
\text { endophthalmitis }\end{array}$} & \multirow{2}{*}{$\begin{array}{l}\text { Number of } \\
\text { patients }\end{array}$} & \multirow{2}{*}{$\begin{array}{l}\text { Average } \\
\text { age } \\
\text { (years) }\end{array}$} & \multicolumn{2}{|l|}{ Gender } & \multirow{2}{*}{$\begin{array}{l}\text { Average } \\
\text { follow- } \\
\text { up } \\
\text { (days) }\end{array}$} \\
\hline & & & Male & Female & \\
\hline Post-traumatic & $\begin{array}{l}113 \\
(55.94 \%)\end{array}$ & 24.2 & $86.73 \%$ & $13.27 \%$ & 248 \\
\hline Endogenous & $29(14.36 \%)$ & 37.4 & $51.72 \%$ & $48.28 \%$ & 371 \\
\hline $\begin{array}{l}\text { Acute post- } \\
\text { operative }\end{array}$ & $21(10.40 \%)$ & 60.8 & $47.62 \%$ & $52.38 \%$ & 607 \\
\hline Keratitis-induced & 14 (6.93\%) & 53.6 & $78.57 \%$ & $21.43 \%$ & 266 \\
\hline $\begin{array}{l}\text { Chronic post- } \\
\text { operative }\end{array}$ & 11 (5.44\%) & 61.5 & $27.27 \%$ & $72.73 \%$ & 375 \\
\hline Bleb-associated & 8 (3.96\%) & 50.3 & $50.00 \%$ & $50.00 \%$ & 323 \\
\hline Suture-associated & $6(2.97 \%)$ & 39.7 & $50.00 \%$ & $50.00 \%$ & 87 \\
\hline
\end{tabular}

conservatively as these were in beginning phthisis. The best corrected visual acuities (BCVA) at 90 days postoperatively was at most $20 / 400$. However, patients seen and managed by the External Disease and Cornea service alone, to which all endophthalmitis patients are initially referred, were not included in the study population. There was also a lack of keratitis-induced cases in their study. In addition, some subgroups were not analyzed separately, such as acute from chronic post-operative cases, and bleb-associated cases from other postoperative cases. Microbial profile analysis was also limited to reporting the top causative organisms. Lastly, the reported visual outcomes do not represent the BCVA past 90 days, when they might have improved further.

Treatment of endophthalmitis is challenging, and identification of risk factors and causative organisms is part of successful management. At present, there is still limited information available regarding endophthalmitis cases in the Philippines. There are also no reported microbial profiles and long-term visual outcomes to date. This study aims: [1] to determine the incidence and etiology of endophthalmitis over a ten-year period, and for each type, the following: associated risk factors, causative pathogens, management, and visual outcomes; and [2] to compare the results of the study to existing literature.

\section{Methods}

This study is a single center, retrospective review of all endophthalmitis cases diagnosed at the DOVS-PGH in Manila, Philippines, over a ten-year period from January 1, 2007 to December 31, 2016. Cases were classified according to their etiology, and data pertaining to history, associated risk factors, isolated microorganisms, management, and final visual outcomes for each patient were reviewed and analyzed. The study was conducted according to the tenets of the Declaration of Helsinki and was approved by the Research Ethics Board of the University of the Philippines - Manila.

\section{Results}

A total of 223 endophthalmitis cases within the 10-year audit period were retrieved, amounting to an average of 22 new endophthalmitis cases seen annually. Two hundred and two endophthalmitis cases were analyzed in this review after exclusion of 21 cases due to incomplete data.

\section{Demographic data}

The cases were classified into seven types of endophthalmitis according to etiology and, for post-operative cases, their course (Table 1). The most common was posttraumatic, accounting for more than half of all cases (55.94\%). This was followed by endogenous

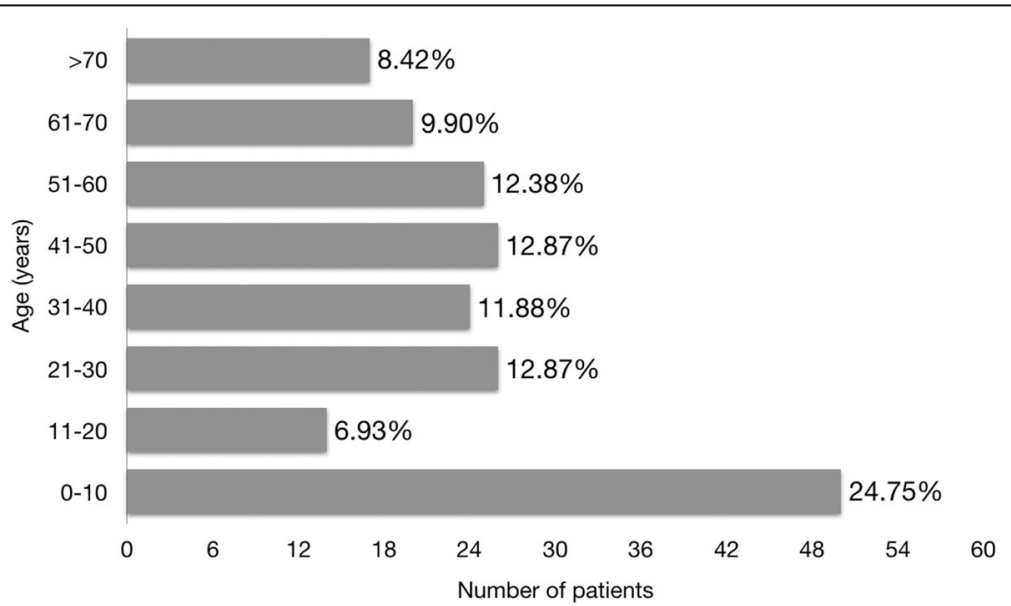

Fig. 1 Age distribution of endophthalmitis cases $(n=202)$. The largest age group affected was 10 years old and below, constituting one-fourth of the cases, while at least half of the patients were within the working age group 


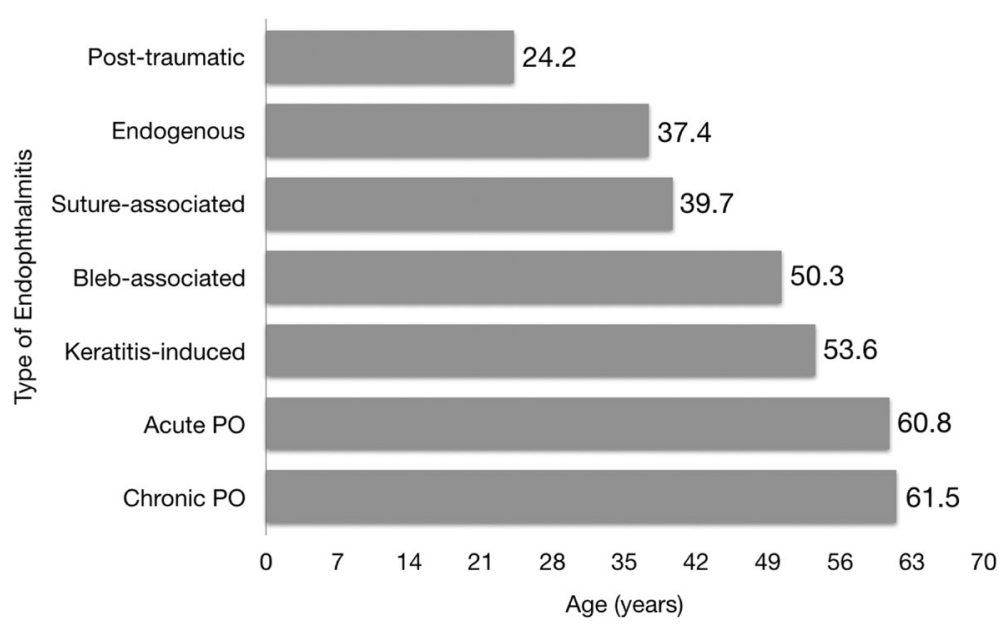

Fig. 2 Mean age by cause of endophthalmitis $(n=202)$. Post-traumatic cases were of younger age on average (24.2 years) compared to acute and chronic post-operative cases (60.8 and 61.5 years, respectively), most of whom had undergone cataract surgery. $\mathrm{PO}=$ post-operative

endophthalmitis at $14.36 \%$ and acute post-operative endophthalmitis at $10.40 \%$. Among 46 patients with preceding surgery (acute and chronic post-operative, blebassociated, and suture-associated cases), 22 (47.83\%) had been performed at the DOVS-PGH. The male to female ratio was 2.5:1 overall, and was highest at $6.5: 1$ in the post-traumatic group. The average duration of follow-up was 309 days.

The mean patient age in our study was 35.5 years. The most commonly affected age group was 0-10 years, which accounted for one-fourth of all cases (Fig. 1). Patients of working age constituted at least half of the population.

Figure 2 shows the groups according to mean age. The post-traumatic endophthalmitis group had the youngest mean age of 24.2 years, while acute and chronic postoperative cases were at the other end of the spectrum with mean ages of 60.8 and 61.5 years, respectively. This is due to the majority of the latter groups having preceding cataract surgeries.

\section{Culture results}

Most of the cases (170; 84.16\%) had ocular samples (vitreous, aqueous, intraocular lens (IOL), IOFB, posterior capsule, corneal scraping, conjunctival swab) sent for microbial analysis. Of the 95 cases with retrieved culture results, 55 (57.89\%) were positive and 40 (42.11\%) were negative. Culture positivity among the different groups is shown in Fig. 3. The highest rates were seen in keratitis-induced, bleb-associated and suture-associated

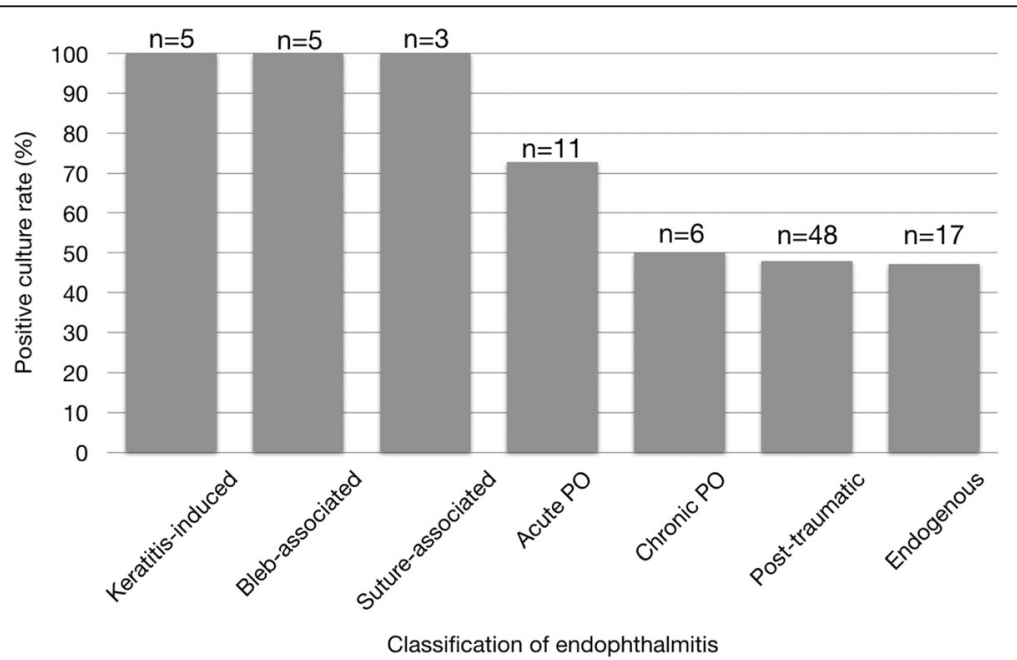

Fig. 3 Positive rates of microbial cultures among the different groups $(n=95)$. Albeit fewer, keratitis-induced, bleb-associated, and sutureassociated cases had high culture positivity rates, while only around half of chronic post-operative, post-traumatic, and endogenous cases yielded positive cultures. $\mathrm{PO}=$ post-operative 


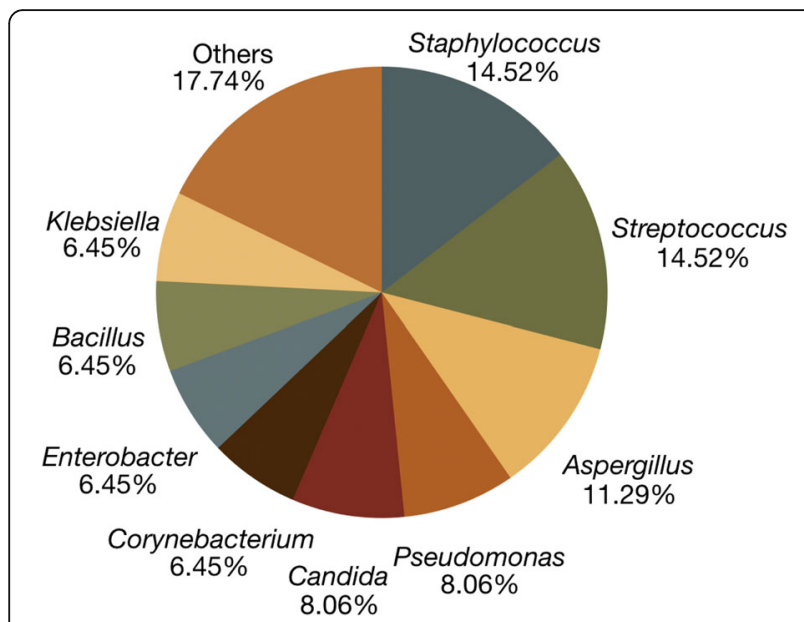

Fig. 4 Most common organisms among microbial isolates identified $(n=62)$. The most prevalent organisms were Staphylococcus and Streptococcus species. Aspergillus and Pseudomonas in addition to these made up half of all organisms identified by culture

endophthalmitis, while the lowest rates were seen in chronic post-operative, post-traumatic, and endogenous endophthalmitis.

Gram-positive organisms were responsible for $38.18 \%$ of culture-positive cases, Gram-negative and mixed pathogens each for $21.82 \%$, and fungi for $18.18 \%$. Among 62 microbial isolates obtained from the 55 culture-proven cases, the most common organisms were Staphylococcus and Streptococcus (14.5\% each) (Fig. 4). Other common organisms were Aspergillus (11.3\%), Pseudomonas, and Candida (8.1\% each). The aforementioned organisms in total made up $56.45 \%$ of isolates.

Table 2 summarizes the profile of causative microorganisms among the different types of endophthalmitis. Gram-positive organisms were more predominant in post-traumatic and endogenous infections, while there was an even distribution of organisms in acute postoperative cases. Fungi were more predominant in keratitis-induced and chronic post-operative endophthalmitis. Gram-positive bacteria and mixed pathogens were mostly seen in bleb-associated endophthalmitis, while Gram-positive, Gram-negative, and mixed infections were equally associated with suture-related endophthalmitis.

\section{Management}

Overall, $62.87 \%$ of patients underwent PPV, $23.27 \%$ received intravitreal and other antibiotics, $10.89 \%$ underwent primary enucleation or evisceration, and $2.97 \%$ underwent other surgeries without vitrectomy. Among the different groups, keratitis-induced cases had the highest rates of primary evisceration and enucleation at 28.6\% (Table 3). PPV was done for most cases except in endogenous and keratitis-induced endophthalmitis where medical management was the mainstay. The average time to surgery (excluding evisceration and enucleation) was 3.3 days. For post-traumatic cases, the average time was 2.7 days.

\section{Final outcomes}

Around three-fourths of all patients had no to poor vision at discharge (Fig. 5). Almost $12 \%$ of patients became anophthalmic, while $12.89 \%$ recovered to $3 / 200$ to 20 / 50, and $9.28 \%$ recovered to at least 20/40 BCVA. Overall, only $21.7 \%$ patients had improved BCVA from presentation. Visual outcomes for eight young pre-verbal children with vision better than no light perception (NLP) or no dazzle were not included in this analysis.

The endogenous endophthalmitis group had the highest proportion of patients who worsened to NLP or no dazzle (Table 4). Acute and chronic post-operative endophthalmitis patients had the greatest rates of recovery to at least 20/40 BCVA.

\section{Post-traumatic endophthalmitis}

More than two thirds of the 113 patients were male (86.73\%) (Table 1). The largest age group affected was 0-9 years old $(31.86 \%)$, with ocular trauma usually occurring due to lack of supervision and failure to remove sharp or pointed objects from the child's vicinity. Injury was most frequently caused by barbecue sticks or walis tingting (native whisk broom) (22.12\%) (Fig. 6). Other common offending agents were metal nails (20.35\%), wires (16.81\%), and metal fragments (14.16\%). At least half of post-traumatic cases was due to the use of

Table 2 Distribution of causative pathogens among the different groups $(n=55)$. Mixed cultures yielded a combination of Grampositive, Gram-negative, and/or fungal isolates. Gram-positive bacteria were predominant in the post-traumatic and endogenous groups, fungi in the chronic post-operative and keratitis groups, and mixed pathogens in the bleb-associated group

\begin{tabular}{|c|c|c|c|c|c|c|c|}
\hline Pathogen & Post-traumatic $(\boldsymbol{n}=23)$ & Endogenous $(\boldsymbol{n}=8)$ & $\begin{array}{l}\text { Acute PO } \\
(\boldsymbol{n}=8)\end{array}$ & Chronic PO $(\boldsymbol{n}=3)$ & $\begin{array}{l}\text { Keratitis } \\
(\boldsymbol{n}=5)\end{array}$ & Bleb $(\boldsymbol{n}=5)$ & Suture $(\boldsymbol{n}=3)$ \\
\hline Gram-positive bacteria & $52.2 \%$ & $37.5 \%$ & $25.0 \%$ & $0 \%$ & $20.0 \%$ & $40.0 \%$ & $33.3 \%$ \\
\hline Gram-negative bacteria & $30.4 \%$ & $12.5 \%$ & $25.0 \%$ & $0 \%$ & $20.0 \%$ & $0 \%$ & $33.3 \%$ \\
\hline Fungi & $4.3 \%$ & $25.0 \%$ & $25.0 \%$ & $66.67 \%$ & $40.0 \%$ & $20.0 \%$ & $0 \%$ \\
\hline Mixed pathogens & $13.0 \%$ & $25.0 \%$ & $25.0 \%$ & $33.33 \%$ & $20.0 \%$ & $40.0 \%$ & $33.3 \%$ \\
\hline
\end{tabular}


Table 3 Management of endophthalmitis cases among the different groups $(n=202)$. The majority of patients underwent PPV except in the endogenous and keratitis groups where management was mostly medical. Keratitis-induced endophthalmitis was associated with the highest rates of primary evisceration and enucleation

\begin{tabular}{|c|c|c|c|c|c|c|c|}
\hline Management & $\begin{array}{l}\text { Post-traumatic } \\
(\boldsymbol{n}=113)\end{array}$ & $\begin{array}{l}\text { Endogenous } \\
(\boldsymbol{n}=29)\end{array}$ & $\begin{array}{l}\text { Acute PO } \\
(\boldsymbol{n}=21)\end{array}$ & $\begin{array}{l}\text { Chronic PO } \\
(\boldsymbol{n}=11)\end{array}$ & $\begin{array}{l}\text { Keratitis } \\
(\boldsymbol{n}=14)\end{array}$ & $\begin{array}{l}\text { Bleb } \\
(\boldsymbol{n}=8)\end{array}$ & $\begin{array}{l}\text { Suture } \\
(\boldsymbol{n}=6)\end{array}$ \\
\hline $\begin{array}{l}\text { Pars plana vitrectomy }+/- \text { other } \\
\text { procedures }\end{array}$ & $77.0 \%$ & $20.7 \%$ & $71.4 \%$ & $54.5 \%$ & $21.4 \%$ & $75.0 \%$ & $66.7 \%$ \\
\hline $\begin{array}{l}\text { Intravitreal and other antibiotics } \\
\text { only }\end{array}$ & $7.96 \%$ & $69.0 \%$ & $19.0 \%$ & $36.4 \%$ & $50.0 \%$ & $25.0 \%$ & $16.7 \%$ \\
\hline $\begin{array}{l}\text { Primary Evisceration or } \\
\text { enucleation }\end{array}$ & $12.4 \%$ & $10.3 \%$ & $0 \%$ & $0 \%$ & $28.6 \%$ & $0 \%$ & $16.7 \%$ \\
\hline
\end{tabular}

$\mathrm{PO}=$ post-operative

industrial tools. Although most of these events were due to lack of eye protection during carpentry and construction work, some still occurred despite protective eyewear having been worn.

Associated factors for infection noted in our patients include the following: delayed consult and increased time to vitrectomy, posterior capsule rupture and vitreous loss, presence of an IOFB and/or retinal detachment, and preoperative topical steroid use. Delay in consult was usually due to occurrence of trauma in rural areas, or primary repair without vitrectomy done previously at a different institution. Preoperatively, retinal detachment was seen in 15.93\% of patients, while $13.27 \%$ was documented pre- or intraoperatively to have an IOFB. At least 17 patients (15.04\%) had prior topical steroid use, four of whom had undergone primary repair elsewhere.

Among 23 culture-positive cases, bacteria represented $82.6 \%$, mixed pathogens $13.0 \%$, and fungi only 4.3\% (Table 2). Gram-positive bacteria were more commonly isolated than Gram-negative bacteria

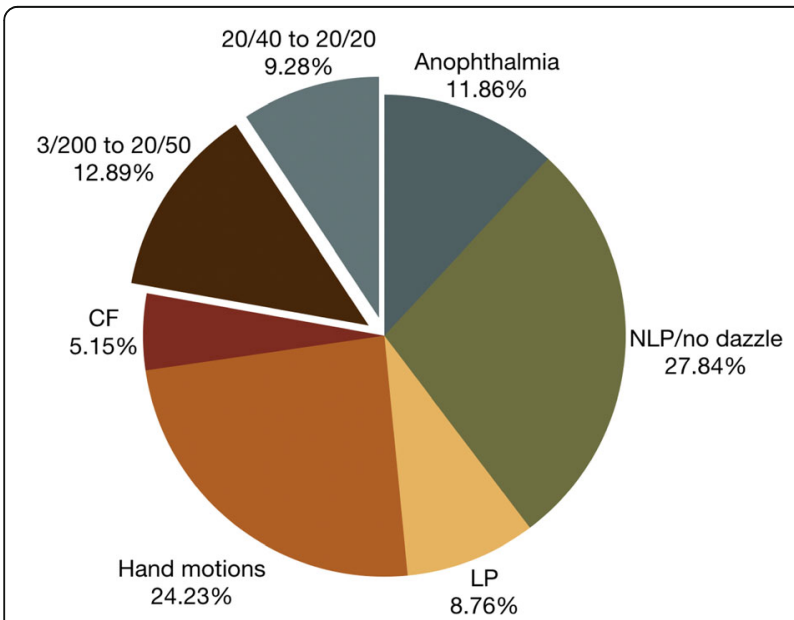

Fig. 5 Final best corrected visual acuities of patients at discharge $(n=$ 194), exluding eight pre-verbal children with vision better than NLP or no dazzle. Forty percent of patients either lost the globe or lost all vision. Only $22 \%$ of patients were left with useful vision. NLP $=$ no light perception; $\mathrm{LP}=$ light perception; $C F=$ counting fingers
(52.2\% and 30.4\%, respectively). Among the most common organisms were Streptococcus, Staphylococcus, Enterobacter, and Aspergillus. Phthisis developed in 26 cases $(26.80 \%, n=97)$, while two cases were already in phthisis because of late consult. The average age of these patients was 20.3 years, $53.5 \%$ of whom were pediatric cases.

\section{Endogenous endophthalmitis}

Diabetes mellitus, dental cavities, urinary tract infection, lung disease, and sepsis were the most common systemic co-morbidities among the 29 patients with endogenous endophthalmitis (Table 5). Some patients had more than one risk factor, including all five patients with sepsis who also had diabetes. Only $10.34 \%$ of endogenous endophthalmitis cases were bilateral, with all having known co-morbidities. However, no predisposing factor could be identified in $17.24 \%$ of patients.

The most common organisms retrieved from eight culture-positive cases were Bacillus, Corynebacterium, and Aspergillus. Four patients presented with panophthalmitis, three of whom were known diabetics. Three of these patients underwent evisceration/enucleation while one developed phthisis bulbi. Phthisis developed in a total of nine out of 25 patients (36.0\%), excluding one case with phthisis at consult. Six of these patients had been medically managed only, while two had undergone surgery.

\section{Acute post-operative endophthalmitis}

Most of the 21 patients (71.43\%) had undergone cataract surgery, with phacoemulsification accounting for more than half of all cases (57.14\%). The ratio of phacoemulsification to extracapsular cataract extraction (ECCE) procedures was 13:1, while one case remained unspecified. Among these patients, ten had an intact posterior capsule with posterior chamber IOL, two patients had intraoperative vitreous loss, while three patients had incomplete documentation. PPV as the preceding surgery accounted for $19.05 \%$ of cases, half of which were done for phacoemulsification complications. 
Table 4 Final BCVA among the different groups $(n=194)$, excluding eight pre-verbal children with vision better than NLP or no dazzle. The acute post-operative and bleb-associated groups had the best outcomes, while the endogenous and keratitis groups had the worst outcomes

\begin{tabular}{|c|c|c|c|c|c|c|c|}
\hline Outcome & $\begin{array}{l}\text { Post-traumatic } \\
(\boldsymbol{n}=106)\end{array}$ & $\begin{array}{l}\text { Endogenous } \\
(\boldsymbol{n}=28)\end{array}$ & $\begin{array}{l}\text { Acute PO } \\
(\boldsymbol{n}=21)\end{array}$ & $\begin{array}{l}\text { Chronic PO } \\
(\boldsymbol{n}=11)\end{array}$ & $\begin{array}{l}\text { Keratitis } \\
(\boldsymbol{n}=14)\end{array}$ & $\begin{array}{l}\text { Bleb } \\
(\boldsymbol{n}=8)\end{array}$ & $\begin{array}{l}\text { Suture } \\
(\boldsymbol{n}=6)\end{array}$ \\
\hline Anophthalmia & $13.2 \%$ & $10.7 \%$ & $4.8 \%$ & $0 \%$ & $28.6 \%$ & $0 \%$ & $16.7 \%$ \\
\hline NLP/no dazzle & $23.6 \%$ & $60.7 \%$ & $19.0 \%$ & $18.2 \%$ & $28.6 \%$ & $25.0 \%$ & $0 \%$ \\
\hline LP & $9.4 \%$ & $3.6 \%$ & $14.3 \%$ & $9.1 \%$ & $7.1 \%$ & $12.5 \%$ & $0 \%$ \\
\hline HM & $28.3 \%$ & $10.7 \%$ & $19.0 \%$ & $27.3 \%$ & $21.4 \%$ & $12.5 \%$ & $50.0 \%$ \\
\hline Counting Fingers & $4.7 \%$ & $0 \%$ & $4.8 \%$ & $18.2 \%$ & $0 \%$ & $12.5 \%$ & $16.7 \%$ \\
\hline $3 / 200$ to $20 / 50$ & $9.4 \%$ & $14.3 \%$ & $23.8 \%$ & $9.1 \% 9.1 \%$ & $7.1 \%$ & $37.5 \%$ & $16.7 \%$ \\
\hline $20 / 40$ to $20 / 20$ & $11.3 \%$ & $0 \%$ & $14.3 \%$ & $18.2 \%$ & $7.1 \%$ & $0 \%$ & $0 \%$ \\
\hline
\end{tabular}

$\mathrm{NLP}=$ no light perception, $\mathrm{LP}=$ light perception, $\mathrm{HM}=$ hand motions

Vitreous loss was documented in only $27.78 \%$ of all patients (excluding those with incomplete documentation). Risk factors in this group were multiple consecutive procedures for complicated cataract surgeries, poor patient hygiene, and suture dehiscence following anterior chamber IOL implantation. Associated factors among those without a history of vitreous loss include scleral perforating injury from a metal nail, use of a re-sterilized phacoemulsification cassette, and persistent intraoperative iris prolapse. Diabetes was documented in $23.81 \%$ of patients in this group. No risk factor however could be identified in $19.05 \%$ of patients.

There was an equal prevalence of Gram-positive, Gram-negative, fungal, and mixed pathogens among the eight cases which yielded positive cultures (Table 2). The most commonly isolated organisms were Candida and Pseudomonas. PPV with IOL explant or other procedures were done for most patients (Table 3). Two of four patients regained vision with medical management only. Secondary evisceration was done for one

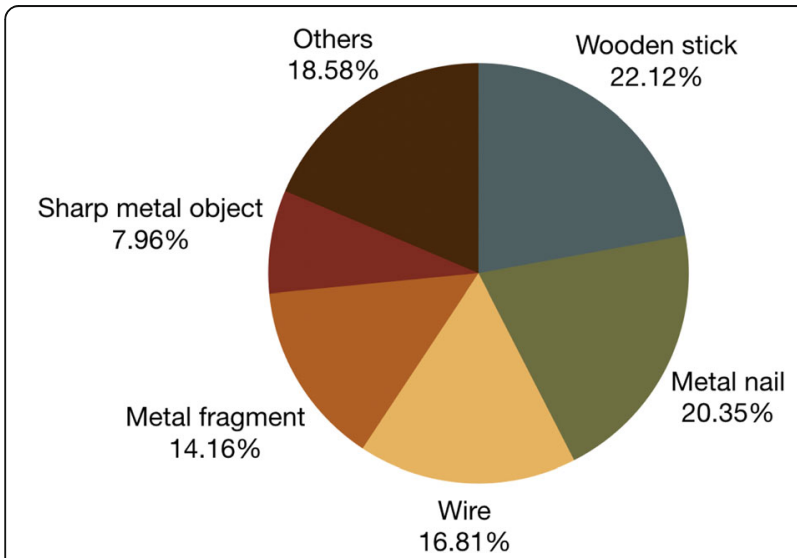

Fig. 6 Offending agents in post-traumatic endophthalmitis cases $(n=113)$. Wooden sticks were the most common traumatic objects and were often associated with pediatric cases. Metal nails, wires, and metal fragments were also among the most frequently identified offending agents patient, after initial PPV and IOL explant; this was the only patient in the group who became anophthalmic.

\section{Chronic post-operative endophthalmitis}

Most patients who had chronic infection developed symptoms within five months from surgery. Only six of 11 (54.55\%) patients had previous cataract surgery, slightly less than that in the acute group. The numbers of phacoemulsification and ECCE procedures were comparable (two and three, respectively). Three had an intact posterior capsule with posterior chamber IOL implant, one had intraoperative vitreous loss, while two had incomplete documentation. Of the three patients with an intact posterior capsule, two had no identified risk factor while one was documented to have a loose suture over the main wound, possibly causing a slow leak.

Similar to the acute group, $18.18 \%$ of patients developed symptoms after PPV. Indications for surgery had been diabetic retinopathy and epiretinal membrane. In the latter case, the patient's anterior chamber IOL haptic slowly eroded through the sclera and endophthalmitis developed 4.5 years post-operatively. These

Table 5 Identified risk factors for endogenous endophthalmitis $(n=29)$. Diabetes mellitus, dental cavities, and urinary tract infections were the most commonly identified risk factors

\begin{tabular}{ll}
\hline Associated Factor & Number of Patients (\%) \\
\hline Diabetes mellitus & $10(34.48 \%)$ \\
Dental cavities & $8(27.59 \%)$ \\
Urinary tract infection & $8(27.59 \%)$ \\
Lung disease & $6(20.69 \%)$ \\
Sepsis & $5(17.24 \%)$ \\
Non-ocular mass & $2(6.90 \%)$ \\
Chronic kidney disease & $1(3.45 \%)$ \\
Cellulitis & $1(3.45 \%)$ \\
\hline
\end{tabular}


two patients were the only known diabetics in the group (18.18\%).

A history of vitreous loss was noted in $55.56 \%$ of all patients (excluding those with incomplete documentation). Other associated factors include postkeratoplasty for a ruptured Staphylococcus epidermidis ulcer (which developed Cladosporium endophthalmitis), previous retina surgery for an IOFB, and blepharitis.

Of the three cases which yielded positive cultures, two were fungal and one had mixed pathogens (Gram-positive cocci and Gram-negative bacilli) (Table 2). Only one isolate, however, was identified (Cladosporium sp.) as the rest were still for speciation. The main treatment was vitrectomy with or without IOL explant. In addition, $36.4 \%$ of patients were managed medically, with half of these patients regaining vision (Table 3 ).

\section{Keratitis-induced endophthalmitis}

Keratitis-induced endophthalmitis was associated with foreign body trauma, ophthalmic laser procedures and subsequent steroid use, and recent post-keratoplasty for fungal keratitis. Among four patients (28.57\%) who had recently used topical steroids, at least one had not been on any topical antibiotic. Two of the 14 patients presented with a perforated corneal ulcer; one patient had undergone a repeat penetrating keratoplasty (PKP) nine years ago and had recent topical steroid use, while the other had no identifiable risk factor. Half of the patients in this group had no recent history of trauma, ocular surgery, or steroid use. Among these were an adult patient with old measles leukoma and a patient with diabetes.

Among the five cases which had positive cultures, two were fungal (40.0\%), one yielded Gram-positive bacteria (20.0\%), one yielded Gram-negative bacteria (20.0\%), and one had mixed pathogens (Gram-positive and Gram-negative organisms) (20.0\%) (Table 2). Organisms identified were Pseudomonas aeruginosa, Enterobacter, Klebsiella, Fusarium, Aspergillus, and Streptococcus pneumoniae. Half of the patients were medically managed, with one case improving to 20/70 BCVA. Almost a third (28.6\%) of patients underwent enucleation or evisceration, the highest rate in our study.
Among 21.4\% of patients who underwent PPV and/or other procedures, vitrectomy with PKP was done in 14.3\% (two cases), both of which had visual outcomes of hand motions.

\section{Bleb-associated endophthalmitis}

Almost all of the eight cases developed 3-11 years posttrabeculectomy. Only one patient developed endophthalmitis less than 1 year post-operatively, after resuturing for an early bleb leak. Excluding this, the average duration from trabeculectomy to infection was 7.4 years. Three cases had documented use of mitomycin-C during trabeculectomy, while antimetabolite use in the other cases was undocumented. None of the patients in our study were known diabetics, while two cases (25.0\%) had no identifiable risk factor.

A young male with poor history of follow-up was the only patient in this group who developed bilateral consecutive bleb-associated endophthalmitis. Trabeculectomies with mitomycin-C for bilateral juvenile open angle glaucoma were done separately four years ago. The risk factor for this patient for the first eye was poor follow-up and discontinuation of medications, while none was identified for the second eye.

Five cases were culture-positive (40.0\% Gram-positive bacteria, $40.0 \%$ mixed pathogens, and $20.0 \%$ fungi) (Table 2). Isolated microorganisms included Staphylococcus aureus and epidermidis, Streptococcus viridans, and Aspergillus niger. Most of the patients underwent vitrectomy with or without IOL explant $(75.00 \%)$ (Table 3). One of the two patients who were managed medically improved.

\section{Suture-associated endophthalmitis}

The six patients in this group either had preceding removal of sutures, retained long-term sutures, exposed suture knots, or loose sutures. The sutures had been in place from a range of two months to two years. Two patients (retained and loose suture cases) were using topical steroids at the time; the latter did not have concurrent topical antibiotic cover. One patient with a two-year retained suture had washed her eye with tap water for foreign body sensation. Among two patients who had undergone removal of sutures, one was an

Table 6 Distribution of types of endophthalmitis compared to other countries. Asia-Pacific countries showed a higher proportion of post-traumatic cases compared to Canada and the UK

\begin{tabular}{llllllll}
\hline Type of endophthalmitis & $\begin{array}{l}\text { Canada [14] } \\
(\boldsymbol{n}=114)\end{array}$ & $\begin{array}{l}\text { UK [11] } \\
(\boldsymbol{n}=47)\end{array}$ & $\begin{array}{l}\text { New Zealand [15] } \\
(\boldsymbol{n}=106)\end{array}$ & $\begin{array}{l}\text { Our study } \\
(\boldsymbol{n}=202)\end{array}$ & $\begin{array}{l}\text { China [4, 16] } \\
(\boldsymbol{n}=330 ; 1593)\end{array}$ & $\begin{array}{l}\text { Thailand [17] } \\
(\boldsymbol{n}=420)\end{array}$ & $\begin{array}{l}\text { Eastern India [18] } \\
(\boldsymbol{n}=107)\end{array}$ \\
\hline Post-traumatic & $12 \%$ & $2 \%$ & $18.9 \%$ & $55.94 \%$ & $58.5 \%, 82.6 \%$ & $43.1 \%$ & $40.2 \%$ \\
Post-operative* & $47 \%$ & $92 \%$ & $58.5 \%$ & $22.77 \%$ & $20.3 \%, 6.9 \%$ & $32.2 \%$ & $43 \%$ \\
Endogenous & $41 \%$ & $6 \%$ & $16 \%$ & $14.36 \%$ & $18.5 \%, 7.8 \%$ & $3.3 \%$ & $16.8 \%$ \\
Keratitis-induced & - & - & - & $6.93 \%$ & $2.7 \%, 2.7 \%$ & $3.1 \%$ & - \\
\hline
\end{tabular}

*Includes acute and chronic post-operative, and bleb- and suture-associated endophthalmitis 
Table 7 Culture-positivity compared to other studies. Our culture-positivity rate was higher compared to other Asian countries as well as the USA, but lower than in Canada

\begin{tabular}{ll}
\hline Country & Culture-positive rates \\
\hline Canada [14] $(\boldsymbol{n}=\mathbf{8 8})$ & $76 \%$ \\
USA [12] $(\boldsymbol{n}=\mathbf{6 7})$ & $44.4 \%$ \\
Our study $(\boldsymbol{n}=\mathbf{9 5})$ & $57.89 \%$ \\
Eastern India [18] $(\boldsymbol{n}=\mathbf{1 0 7})$ & $42.1 \%$ \\
Southern India [19] $(\boldsymbol{n}=\mathbf{9 5 5})$ & $44.4 \%$ \\
Southern China [4] $(\boldsymbol{n}=\mathbf{3 3 0})$ & $31.8 \%$ \\
Western China [16] $(\boldsymbol{n}=\mathbf{6 7 0})$ & $39.7 \%$ \\
Thailand [17] $(\boldsymbol{n}=\mathbf{4 2 0})$ & $29.1 \%$ \\
\hline
\end{tabular}

uncooperative child and one had only started the topical antibiotic one day later. Only one patient was documented to have diabetes, and had only been diagnosed at our hospital upon workup. Four cases were postcataract surgery (two ECCE and two unspecified), one of whom had intraoperative vitreous loss. One case had undergone phacoemulsification and trabeculectomy, and one case was a secondary IOL implantation.

The three cases with retrieved results had positive cultures with equal prevalence of Gram-positive, Gramnegative, and mixed pathogens (Gram-negative bacteria and fungal) (Table 2). Organisms identified were Staphylococcus sp., Proteus mirabilis, and a mixed infection of Fusarium solani and Acinetobacter lwoffii. Most cases underwent PPV with or without IOL explant (Table 3).

\section{Discussion}

Our population is almost double that of De Sagun-Bella and Santos in their pilot study [10]. In contrast to previous reports from developed countries, including the United States, Canada, New Zealand, and the United Kingdom, where most cases of endophthalmitis are due to intraocular surgery $[6,8,11-13]$, post-traumatic endophthalmitis accounted for the majority of cases (55.94\%) in our study. Our findings however are consistent with reviews done in China and Thailand, where the major etiology of infectious endophthalmitis cases was
Table 9 Causative microorganisms among the different types of endophthalmitis in our study $(n=55)$. Post-traumatic and endogenous cases had a higher prevalence of Gram-positive bacteria, while post-operative and keratitis-induced cases had a relatively high proportion of fungal infections

\begin{tabular}{lllll}
\hline Pathogen & $\begin{array}{l}\text { Post- } \\
\text { traumatic } \\
(\boldsymbol{n}=23)\end{array}$ & $\begin{array}{l}\text { Post- } \\
\text { operative* } \\
(\boldsymbol{n}=19)\end{array}$ & $\begin{array}{l}\text { Endogenous } \\
(\boldsymbol{n}=8)\end{array}$ & $\begin{array}{l}\text { Keratitis- } \\
\text { induced } \\
(\boldsymbol{n}=5)\end{array}$ \\
\hline Gram-positive & $52.2 \%$ & $26.3 \%$ & $37.5 \%$ & $20.0 \%$ \\
Gram-negative & $30.4 \%$ & $15.8 \%$ & $12.5 \%$ & $20.0 \%$ \\
Fungal & $4.3 \%$ & $26.3 \%$ & $25.0 \%$ & $40.0 \%$ \\
Mixed pathogens & $13.0 \%$ & $31.6 \%$ & $25.0 \%$ & $20 \%$ \\
\hline
\end{tabular}

*Includes acute and chronic post-operative, and bleb- and suture-associated endophthalmitis

ocular trauma (Table 6) $[4,16,17]$. Higher rates of ocular injury associated with industrial and agricultural activities in developing countries could be responsible for the dissimilarity of results among the studies [4]. A study conducted in India on the other hand showed comparable rates of post-traumatic and post-operative endophthalmitis [18]. Our respective proportions of postoperative and endogenous endophthalmitis were comparable to other developing countries; however, our proportion of keratitis-induced infections was twice as high compared to studies done in China and Thailand (Table 6).

Post-traumatic endophthalmitis cases were associated with younger age, and acute and chronic post-operative cases with older age as most of the latter had undergone cataract surgeries (Table 1). Male patients represented the majority of our cases, similar to studies in other developing countries where figures ranged from $66.0 \%$ to 79.5\% [16]. This could be because our hospital receives patients of relatively lower economic status and a large number of these cases are industry-related posttraumatic endophthalmitis. Gender-based behavior and engagement of males in higher risk activities may also be contributory reasons [4]. In contrast, there appears to be no gender predilection in developed countries, with a study from Canada reporting 45.6\% males [14].

Our culture-positive rate of $57.89 \%$ is higher compared to the other Asian countries and the USA, but less than that in a Canadian study (Table 7). The spectrum of

Table 8 Microbiologic profile compared to other countries. Our study showed a lower proportion of Gram-positive bacteria, less fungal infections compared to India and southern China, and a higher proportion of mixed pathogen infections

\begin{tabular}{lllllll}
\hline Organism & $\begin{array}{l}\text { Canada [14] } \\
(\boldsymbol{n}=67)\end{array}$ & $\begin{array}{l}\text { Our study } \\
(\boldsymbol{n}=55)\end{array}$ & $\begin{array}{l}\text { Southern China [4] } \\
(\boldsymbol{n}=105)\end{array}$ & $\begin{array}{l}\text { Western China [16] } \\
(\boldsymbol{n}=266)\end{array}$ & $\begin{array}{l}\text { Thailand [17] } \\
(\boldsymbol{n}=122)\end{array}$ & $\begin{array}{l}\text { Eastern India [18] } \\
(\boldsymbol{n}=45)\end{array}$ \\
\hline Gram-positive & $65.7 \%$ & $38.18 \%$ & $45.7 \%$ & $66.5 \%$ & $52.5 \%$ & $42.2 \%$ \\
Gram-negative & $6.0 \%$ & $21.82 \%$ & $28.6 \%$ & $24.1 \%$ & $28.7 \%$ & $26.7 \%$ \\
Fungal & $16.4 \%$ & $18.18 \%$ & $23.8 \%$ & $4.1 \%$ & $6.56 \%$ & $26.7 \%$ \\
Mixed pathogens & $11.9 \%$ & $21.82 \%$ & $1.9 \%$ & $5.3 \%$ & $12.3 \%$ & $4.4 \%$ \\
\hline
\end{tabular}


Table 10 Most common organisms compared to other countries. The most prevalent organisms were Staphylococcus and Streptococcus

\begin{tabular}{|c|c|}
\hline Country & Most common isolates \\
\hline Canada [14] $(n=59)$ & $\begin{array}{l}\text { Staphylococcus, Streptococcus, } \\
\text { Candida, Enterococcus }\end{array}$ \\
\hline USA [21] $(n=\mathbf{3 1 3})$ & $\begin{array}{l}\text { Staphylococcus, Streptococcus, } \\
\text { Propionibacterium acnes }\end{array}$ \\
\hline Australia [6] $(n=229)$ & $\begin{array}{l}\text { Staphylococcus, Streptococcus, } \\
\text { Candida }\end{array}$ \\
\hline Our study $(n=62)$ & $\begin{array}{l}\text { Staphylococcus, Streptococcus, } \\
\text { Aspergillus, Pseudomonas, } \\
\text { Candida }\end{array}$ \\
\hline Southern China [4] $(n=105)$ & $\begin{array}{l}\text { Staphylococcus, Aspergillus, } \\
\text { Fusarium, Pseudomonas }\end{array}$ \\
\hline Thailand [17] $(n=107)$ & $\begin{array}{l}\text { Staphylococcus, Streptococcus, } \\
\text { Pseudomonas, Bacillus }\end{array}$ \\
\hline Eastern India [18] $(\boldsymbol{n}=\mathbf{3 4})$ & $\begin{array}{l}\text { Pseudomonas, Streptococcus, } \\
\text { Staphylococcus, Bacillus, } \\
\text { Aspergillus, Candida }\end{array}$ \\
\hline Southern India [19] $(n=46)$ & $\begin{array}{l}\text { Staphylococcus, Streptococcus, } \\
\text { Pseudomonas, Aspergillus }\end{array}$ \\
\hline
\end{tabular}

organisms partly depends on the geographical location of the patient. Table 8 compares our microbiologic profile to similar retrospective studies. Compared to other developing Asian countries, our study shows a lower proportion of Gram-positive bacteria, less fungal infections compared to India and southern China, and a higher proportion of mixed pathogen infections. This disparity may also be due to more difficult cases being referred to our institution. Some of these patients had been treated for infection before being referred, thereby also potentially altering the initial microbial profile.

A similar study conducted in western China showed Gram-positive bacteria to be the most prevalent across all types of endophthalmitis [16]. In our study, this was only true for post-traumatic and endogenous infections. Post-operative and keratitis-induced cases had a relatively high proportion of fungal infections (Table 9). Our study results are consistent with the literature wherein

Table 11 Management of endophthalmitis cases compared to other studies. Our study showed a higher frequency of PPV and a lower frequency of primary enucleation and evisceration compared to other Asian countries

\begin{tabular}{lllll}
\hline Management & $\begin{array}{l}\text { Canada [14] } \\
(\boldsymbol{n}=114)\end{array}$ & $\begin{array}{l}\text { Our study } \\
(\boldsymbol{n}=202)\end{array}$ & $\begin{array}{l}\text { Western } \\
\text { China [16] } \\
(\boldsymbol{n}=266)\end{array}$ & $\begin{array}{c}\text { Thailand [17] } \\
(\boldsymbol{n}=122)\end{array}$ \\
\hline $\begin{array}{l}\text { Pars plana } \\
\text { vitrectomy }\end{array}$ & $70.8 \%$ & $62.87 \%$ & $51.3 \%$ & $45.0 \%$ \\
$\begin{array}{l}\text { Topical/intravitreal } \\
\text { antibiotics }\end{array}$ & $15.0 \%$ & $23.27 \%$ & $34.8 \%$ & $20.7 \%$ \\
$\begin{array}{l}\text { Primary } \\
\text { enucleation/ } \\
\text { evisceration }\end{array}$ & $3.3 \%$ & $10.89 \%$ & $13.9 \%$ & $17.9 \%$ \\
\hline
\end{tabular}

Table 12 Final visual outcomes compared to other countries. Only $21.7 \%$ of patients in our study had improved BCVA upon discharge

\begin{tabular}{ll}
\hline Country & $\begin{array}{l}\text { Patients with improved } \\
\text { BCVA from baseline (\%) }\end{array}$ \\
\hline Canada [14] $(\boldsymbol{n}=\mathbf{1 1 4})$ & $60 \%$ \\
USA [12] $(\boldsymbol{n}=\mathbf{6 7})$ & $61 \%$ \\
Our study $(\boldsymbol{n}=\mathbf{1 9 4})$ & $21.7 \%$ \\
Western China [16] $(\boldsymbol{n}=\mathbf{1 4 2 4})$ & $34.4 \%$ \\
Thailand [17] $(\boldsymbol{n}=\mathbf{4 2 0})$ & $60.2 \%$ \\
\hline
\end{tabular}

Staphylococcus and Streptococcus are the most common causative organisms (Table 10) [2, 20]. Aspergillus and Pseudomonas were similarly prevalent in other Asian countries.

In terms of management, our study showed a higher frequency of PPV and a lower frequency of primary enucleation and evisceration compared to other Asian countries (Table 11). However, only $21.7 \%$ of our patients had an improvement in BCVA from presentation. This was one-third of the rates seen in Canada, USA, and Thailand, and was slightly lower than that reported in China (Table 12).

\section{Post-traumatic endophthalmitis}

Compared to post-operative endophthalmitis, a greater variety of organisms are found in post-traumatic endophthalmitis since these are derived from the environment [20]. Bacteria cause around $80-90 \%$ of culturepositive post-traumatic endophthalmitis [1]. Worldwide, coagulase-negative Staphylococcus (i.e., S. epidermidis and S. saprophyticus) and Streptococcus remain the most common isolates, which was also seen in our study. Other significant organisms are Pseudomonas, Enterobacter, and Bacillus, with prevalence depending on the geographic location [2, 20]. A 20-year retrospective study done in China reported fungi among $17.3 \%$ of isolates, with Aspergillus also being most commonly identified [22]. Virulent organisms associated with posttraumatic endophthalmitis are Bacillus cereus and Staphylococcus aureus $[2,8,20]$. In our study, Bacillus, Enterobacter, and Klebsiella were retrieved from eyes that eventually required evisceration or enucleation.

The majority of patients underwent vitrectomy and repair (Table 3). Patients who underwent PPV generally had better outcomes compared to those who had anterior, core, or no vitrectomy, even if it was only done later after primary repair. Other factors associated with poorer outcomes including phthisis bulbi and anophthalmia were delay in consult, panophthalmitis, mixed pathogen infections, and temporary keratoprosthesis use to facilitate view for PPV. Delayed consult could have entailed increased time to vitrectomy, as well 
as post-operative steroid use after primary repair but prior to vitrectomy.

Post-traumatic endophthalmitis carries a generally poor visual prognosis. A final vision of NLP was reported in one study to be $22.7 \%$, and hand motions or worse to be $45 \%$ [23]. Our study showed poorer visual recovery, with almost three-fourths of patients having final visual outcomes of hand motions or worse (Table 4). Some studies have shown that only $15 \%-41 \%$ of cases recover vision to $20 / 40$ or better [1,24]. A multicenter prospective study similarly noted a return to visual acuity of at least $20 / 40$ in $41 \%$ of cases while $35 \%$ progressed to phthisis [23]. In our review, only $11.3 \%$ of post-traumatic endophthalmitis cases achieved $20 / 40$ or better (Table 4), while phthisis bulbi developed in $26.80 \%$ of cases. Younger age and increased number of surgeries did not appear to be significant risk factors for phthisis.

\section{Endogenous endophthalmitis}

Comorbidities such as diabetes mellitus, malignancy, immunocompromisation, immunosuppressive therapy, intravenous drug use, organ abscess, indwelling catheter, urinary tract infection, organ transplant, end-stage renal or liver disease, and endocarditis can predispose patients to the development of endogenous endophthalmitis. It is highly uncommon for patients with endogenous endophthalmitis to have no risk factors for systemic infection, although there have been reports of endogenous endophthalmitis in healthy, immunocompetent individuals without any apparent loci of extraocular infection [2]. Diabetes in particular has been cited as the most common predisposing condition in this group [14, 25], as in our study (Table 5 ).

The microorganisms in culture-positive cases vary from study to study and is also affected by geographic location [1]. Some are more likely to be found in certain diseases, such as Staphylococcus aureus and Streptococcus sp. in endocarditis, and Klebsiella pneumoniae in liver abscess. Long-term hospitalization has also been implicated in endophthalmitis from Candida sp. (especially albicans), and filamentous fungi such as Aspergillus [13]. Fungi were the most commonly identified pathogens in several studies, notably Candida albicans followed by Aspergillus. Endogenous endophthalmitis has also been reported to be caused mainly by Grampositive bacteria in the west, and by Gram-negative bacteria (specifically Klebsiella) in East Asian countries [1]. The majority of the isolates in our study, however, were Gram-positive bacteria. The only Gram-negative organism identified was Klebsiella from a diabetic patient who had a urinary tract infection. Aspergillus was also one of the most common organisms for this group in our study. Non-ocular cultures were positive in three cases, and in one case the blood culture result correlated with the ocular culture (methicillin-resistant Staphylococcus aureus).

In addition to systemic therapy for treating the focus of infection in endogenous endophthalmitis, PPV should be strongly considered if there is no response to initial treatment or if the condition is considered severe and sight-threatening [26]. The majority of our cases received medical management only (69.0\%) (Table 3$)$. The case with the best visual outcome in the group (20/50), however, had undergone PPV.

Visual prognosis is often poor in both bacterial and fungal endogenous endophthalmitis [2]. Aspergillus species have been associated with the worst final visual outcomes and Candida species with the best [1, 27]. Another study reported that a final visual acuity of at least 20/200 was achieved in $80 \%$ of eyes with Candida isolates, and in only $18 \%$ of cases caused by Grampositive bacteria [28]. In our study, Aspergillus was isolated from one of the three cases which required evisceration/enucleation, while Bacillus was the only organism associated with better than NLP outcomes. Mixed pathogens were retrieved from $25.0 \%$ of cases (Table 2), all of whom had final visual outcomes of NLP or no dazzle.

A meta-analysis which included endogenous endophthalmitis cases from reported that a final visual acuity of $20 / 200$ or better was attained by $41 \%$ of eyes, while $19 \%$ eventually required enucleation or evisceration [1]. In an East Asian study, only $28 \%$ of cases regained good visual acuity [2]. In contrast, only $14.3 \%$ of patients in our study achieved at least 3/200 final BCVA, and none improved to $20 / 40$ or better (Table 4). Also, evisceration/ enucleation was done in only $10.3 \%$ of cases (Table 3 ). Phthisis bulbi developed in $36.0 \%$ of patients, the majority of which had been only managed medically.

\section{Acute post-operative endophthalmitis}

Known risk factors for post-operative endophthalmitis also documented in our study include diabetes mellitus, older age, intraoperative complications, posterior capsular rent, vitreous loss, less experienced surgeons, and wound leak [1]. Posterior capsular rent has been shown to increase the risk of acute endophthalmitis by as much as 8 to 11-fold [31]. Vitreous loss however was documented in only $27.78 \%$ of patients in our study.

Among those who underwent cataract surgery in this group, phacoemulsification significantly outnumbered ECCE procedures. This could also be attributed to more phacoemulsification procedures being performed in our institution. It is still debatable whether there is an increased risk of acute endophthalmitis after ECCE compared to phacoemulsification. Some studies have shown a higher incidence after phacoemulsification [5, 31], some studies showed the opposite conclusion [32-34], 
while others have found no difference between the two surgical techniques [35].

The most commonly reported causative microorganisms in acute post-operative endophthalmitis are coagulase-negative staphylococci, Staphylococcus aureus, streptococci, other Gram-positive cocci, including enterococci and mixed bacteria, and Gram-negative bacilli. The usual pathogenesis, contamination of the aqueous humor with surface bacteria during surgery, is reflected in the fact that Gram-positive bacteria cause more than 95\% of these cases [3]. However, two studies from India reported that the incidence of Gram-positive and Gramnegative bacteria were approximately equal. There was also a higher incidence of Pseudomonas aeruginosa endophthalmitis [2].

Though less common than bacterial endophthalmitis, fungal endophthalmitis can also occur post-cataract surgery with the majority also presenting acutely [2]. In tropical regions such as India, fungi may cause 10-15\% and as high as $17-22 \%$ of post-operative endophthalmitis cases $[1,3]$. Similar to the studies from India, Grampositive and Gram-negative bacteria were also of equal incidence among the isolates in our study. However, our study showed a higher incidence of fungal endophthalmitis at $27.27 \%$.

The visual outcome is dependent on the causative organism. Eyes with a final visual acuity of worse than 20/ 200 are reportedly more likely to be associated with Streptococcus, while coagulase-negative Staphylococcus was more prevalent in eyes that recovered to $20 / 40$ or better [1]. In contrast, one case which worsened to NLP in our study was due to Staphylococcus lugdunensis, while 20/40 to 20/20 BCVA was regained in cases from Blastoschizomyces capitatus, Escherichia coli, and a mixed pathogen case with Candida albicans, Pseudomonas aeruginosa, and anaerobic Gram-positive cocci.

Another study reported that $50 \%$ of eyes with postcataract endophthalmitis achieved 20/40 vision, while $10 \%$ declined to a final visual acuity of $5 / 200$ or worse [3]. In our review, $61.9 \%$ deteriorated to counting fingers or worse, while only $14.3 \%$ regained at least $20 / 40$ BCVA (Table 4).

\section{Chronic post-operative endophthalmitis}

Aside from blepharitis, risk factors documented in our study were similar to those in the acute post-operative group. Compared to $27.78 \%$ of patients in the acute group, $55.56 \%$ of patients in this group had a history of vitreous loss. The numbers of phacoemulsification and ECCE surgeries were similar, in contrast to significantly more phacoemulsification than ECCE procedures in the acute group.

Propionibacterium acnes is the most common pathogen to be isolated in chronic post-operative endophthalmitis, accounting for 41-63\% of culture-proven cases [1]. Other reported bacteria include Staphylococcus sp. (especially epidermidis), filamentous bacteria (including Actinomyces and Nocardia sp.), and Enterococcus faecalis [2]. Fungi are also significant causative pathogens, having been reported in $16-27 \%$ of these cases [1]. In our study, only Cladosporium was positively identified as a causative organism. Chronic post-operative endophthalmitis carries a generally better visual prognosis compared to the acuteonset type. One study reported that $50 \%$ of chronic cases improved to a final visual acuity of better than 20/40 compared to $27 \%$ of acute-onset cases [29]. In our study, however, only $18.2 \%$ of cases in the chronic group improved to at least 20/40 BCVA, compared to a slightly lower $14.3 \%$ in the acute group.

Another study found that in cases of chronic postoperative endophthalmitis, eyes infected with $P$. acnes had better final visual outcomes than fungal cases, where more than $20 \%$ of eyes had final vision worse than 20 / 200 [30]. In our review, both fungal cases similarly had poor outcomes of NLP and hand motions.

\section{Keratitis-induced endophthalmitis}

Known risk factors for keratitis-induced endophthalmitis that were observed in this group include use of topical steroids, older age, diabetes mellitus, foreign body injury, and organic matter exposure, and corneal perforation [9]. One patient with diabetes had recently undergone keratoplasty at another institution for Fusarium solani keratitis. Although steroids had been withheld postoperatively, progression to endophthalmitis could be due to the organism's ability to penetrate an intact cornea [9].

In a 15 -year retrospective study by Henry et al., fungi were reported to be the most common organisms, followed by Gram-positive bacteria and Gram-negative bacteria [9]. Another 14-year retrospective study however reported Gram-positive bacteria in $36.9 \%$ of cases, followed by Gram-negative bacteria in $18.4 \%$, fungi in $10.5 \%$, and no growth or unknown organism in $31.6 \%$ [36]. Both studies were conducted in the United States. Among the isolates in our study, in contrast, most common were Gram-negative bacteria, followed equally by Gram-positive bacteria and fungi.

The most common microbial isolates documented by Henry et al. in their study were Fusarium, Candida, Streptococcus pneumoniae, and Pseudomonas aeruginosa [9], which were also identified in our study. The recent post-keratoplasty case with Fusarium solani eventually underwent evisceration, while NLP outcome was seen in a mixed pathogen case with Pseudomonas aeruginosa and Klebsiella pneumoniae.

In the same study by Henry et al., a final visual acuity of $20 / 50$ or better was seen in $14 \%$ of cases, while 
patients with visual acuity worse than $5 / 200$ represented $69 \%$ of the study population. Thirty-one percent of patients required evisceration or enucleation [9], a rate comparable to that in our study (Table 3). In contrast, $85.7 \%$ of our patients declined to counting fingers or worse, and only $7.1 \%$ achieved $20 / 40$ or better BCVA (Table 4).

\section{Bleb-associated endophthalmitis}

Risk factors identified in the patients in our study were poor follow-up, early-onset bleb leak, blepharitis, loose suture, intraoperative use of antimetabolites, and recent eye non-penetrating trauma. However, late-onset bleb leak has been more commonly cited as a risk factor compared to early-onset leak [1]. Younger age, also cited as a risk factor for infection, was not observed in our study as the average age of the patients was 50.3 years. Although the use of antimetabolites, specifically mitomycin- $C$, increases the success rate of trabeculectomies, their use also increases the risk of endophthalmitis 3-fold [1].

The most common pathogens in early bleb-associated endophthalmitis, similar to acute-onset post-operative endophthalmitis, are Staphylococcus epidermidis and Staphyloccocus aureus [1]. The only early-onset case in our study similarly was culture-positive for S. epidermidis. Delayed-onset cases on the other hand are usually caused by Streptococcus sp. and Moraxella catarrhalis [1]. Other gram-negative bacteria (Pseudomonas aeruginosa, Haemophilus influenzae, and Serratia sp.) have been reported as well [2]. Isolates from late-onset infections in our study were Streptococcus viridans, S. aureus, and Aspergillus niger.

The final visual outcome in bleb-associated endophthalmitis varies, but the high prevalence of virulent organisms such as Streptococcus sp. and Gram-negative bacteria make the prognosis unfavorable. Studies have reported an outcome of no light perception (NLP) in $23 \%$ to $35 \%$ of cases [1]. Another series noted a return to at least $20 / 40$ vision in $40 \%$ of cases while $30 \%$ lost all vision in the affected eye [3]. Similarly in our study, $25.0 \%$ of patients had a final visual outcome of NLP or no dazzle, while $37.5 \%$ recovered $3 / 200$ or better BCVA (Table 4). Among those with positive isolates, the worst visual outcome (LP) was due to Streptococcus viridans, while vision was regained in a case due to Staphylococcus epidermidis.

Patients with better vision at presentation also have been shown to obtain better visual outcomes. One study reported that $83 \%$ of patients with initial visual acuity of better than LP achieved a final visual acuity of better than $20 / 40$, while only $31 \%$ of patients with presenting vision of LP were able to attain the same level of improvement [1]. In our study, however, no patient regained at least 20/40 BCVA even among seven patients who presented with better than LP (Table 4).

\section{Suture-associated endophthalmitis}

Associated factors for endophthalmitis in this group were exposed suture knot, topical steroid use without antibiotic cover in a patient who had a loose suture, application of tap water for foreign body sensation, delay in application of topical antibiotic after suture removal, and difficult suture removal in office in an uncooperative child. Although endophthalmitis due to long-term retention of sutures after cataract surgery or penetrating keratoplasty is very rare, the Royal College of Ophthalmologists recommended the removal of corneal sutures within three months following routine extracapsular cataract surgery [7]. Sedation should also be considered for younger children or uncooperative patients.

In the study by Henry et al. which reviewed corneal suture-associated culture-proven endophthalmitis cases over a 15-year period, only six cases were diagnosed with suture-associated endophthalmitis. Five of the isolates were Streptococcus sp. while the remaining was a case with Serratia marcescens [7]. The organisms identified by culture in our study, however, were Staphylococcus, Proteus mirabilis, Fusarium solani and Acinetobacter lwoffii. The case with Staphylococcus was a diabetic patient who presented with a suture abscess and panophthalmitis after cataract surgery (history of vitreous loss was not known), and eventually underwent enucleation. Proteus was isolated from the patient who had washed the eye with tap water; this patient had the best outcome in the group of 20/150 BCVA. Henry et al. reported visual outcomes in their study ranging from 20/150 to NLP [7]. In our review, one patient required enucleation, while final BCVA similarly ranged from 20/150 to hand motions (Table 4).

\section{Conclusions}

Post-traumatic endophthalmitis represented a greater proportion of cases compared to traditional estimates but this was consistent with data from studies in China and Thailand. The majority of these cases involved younger children and young to middle-aged males engaged in carpentry and construction work, implying a need for increased public health eye safety awareness and strengthening of childcare and workplace safety policies. There was a lower proportion of Gram-positive infections and a higher proportion of mixed pathogen infections compared to other studies. We also noted a relatively higher proportion of fungi associated with post-operative and keratitis-induced cases. Final visual outcomes are poorer compared to similar studies in Western and Asian countries, with only $21.7 \%$ of patients improving from presentation and less than $10 \%$ 
recovering to $20 / 40$ or better. Overall, acute postoperative and bleb-associated endophthalmitis showed the best visual outcomes, while endogenous and keratitis-induced endophthalmitis had the poorest visual outcomes. The results of this study identify the profile of endophthalmitis cases at a tertiary referral hospital in the Philippines.

\section{Abbreviations}

BCVA: Best corrected visual acuity; CF: Counting fingers; DOVS : Department of Ophthalmology and Visual Sciences; ECCE : Extracapsular cataract extraction; HM: Hand motions; IOFB: Intraocular foreign body; IOL: Intraocular lens; LP: Light perception; NLP: No light perception; PGH: Philippine General Hospital; PKP: Penetrating keratoplasty; PO: Post-operative; PPV: Pars plana vitrectomy

\section{Acknowledgements}

Not applicable.

\section{Authors' contributions}

VGD collected and interpreted the patient data and wrote the manuscript. RLBS conceptualized the study and gave significant contributions to the revision of the manuscript. Both authors read and approved the final manuscript.

\section{Funding}

This study did not receive any funding

\section{Availability of data and materials}

The datasets used and/or analysed during the current study are available from the corresponding author on reasonable request.

\section{Ethics approval and consent to participate}

The study was conducted according to the tenets of the Declaration of Helsinki and was approved by the Research Ethics Board of the University of the Philippines - Manila.

\section{Consent for publication}

Not applicable.

\section{Competing interests}

The authors declare that they have no competing interests.

Received: 13 January 2020 Accepted: 10 June 2020

Published online: 14 August 2020

\section{References}

1. Vaziri K, Schwartz SG, Kishor K et al (2015) Endophthalmitis: state of the art Clin Ophthalmol 9:95-108. https://doi.org/10.2147/OPTH.S76406 [published Online First: 2015/01/23]

2. Safneck JR (2012) Endophthalmitis: A review of recent trends. Saudi J Ophthalmol 26(2):181-189. https://doi.org/10.1016/j.sjopt.2012.02.011 [published Online First: 2012/04/01]

3. Durand ML (2013) Endophthalmitis. Clin Microbiol Infect 19(3):227-234. https://doi.org/10.1111/1469-0691.12118 [published Online First: 2013/02/27]

4. Duan F, Wu K, Liao J et al (2016) Causative Microorganisms of Infectious Endophthalmitis: A 5-Year Retrospective Study. J Ophthalmol 2016:6764192. https://doi.org/10.1155/2016/6764192 [published Online First: 2016/07/15]

5. Al-Mezaine HS, Al-Assiri A, Al-Rajhi AA (2009) Incidence, clinical features, causative organisms, and visual outcomes of delayed-onset pseudophakic endophthalmitis. Eur J Ophthalmol 19(5):804-811. https://doi.org/10.1177/ 112067210901900519 [published Online First: 2009/09/30]

6. Moloney TP, Park J (2014) Microbiological isolates and antibiotic sensitivities in culture-proven endophthalmitis: a 15-year review. Br J Ophthalmol 98(11): 1492-1497. https://doi.org/10.1136/bjophthalmol-2014-305030 [published Online First: 2014/06/19]

7. Henry CR, Flynn HW Jr, Miller D et al (2013) Delayed-onset endophthalmitis associated with corneal suture infections. J Ophthalmic Inflamm Infect 3(1):
51. https://doi.org/10.1186/1869-5760-3-51 [published Online First: 2013/06/ 14]

8. Kernt M, Kampik A (2010) Endophthalmitis: Pathogenesis, clinical presentation, management, and perspectives. Clin Ophthalmol 4:121-135. https://doi.org/10.2147/opth.s6461 [published Online First: 2010/04/15]

9. Henry CR, Flynn HW Jr, Miller D et al (2012) Infectious keratitis progressing to endophthalmitis: a 15-year study of microbiology, associated factors, and clinical outcomes. Ophthalmology 119(12):2443-2449. https://doi.org/10. 1016/j.ophtha.2012.06.030 [published Online First: 2012/08/04]

10. De Sagun-Bella K, Santos E (2017) Endophthalmitis: diagnosis, management and outcomes at the Philippine General Hospital. 11th Asia-Pacific Vitreoretina Society Congress, Kuala Lumpur

11. Gupta A, Orlans HO, Hornby SJ et al (2014) Microbiology and visual outcomes of culture-positive bacterial endophthalmitis in Oxford, UK. Graefes Arch Clin Exp Ophthalmol 252(11):1825-1830. https://doi.org/10. 1007/s00417-014-2658-7 [published Online First: 2014/07/17]

12. Karacal H, Kymes SM, Apte RS (2007) Retrospective analysis of etiopathogenesis of all cases of endophthalmitis at a large tertiary referral center. Int Ophthalmol 27(4):251-259. https://doi.org/10.1007/s10792-0079068-3 [published Online First: 2007/04/18]

13. Verma A, Muralidharan V, Nigam E (2015) Endophthalmitis: current trends, drugs and protocols. Sci J Med Vis Res Foun XXXII:61-70

14. Krause L, Bechrakis NE, Heimann $\mathrm{H}$ et al (2009) Incidence and outcome of endophthalmitis over a 13-year period. Can J Ophthalmol 44(1):88-94. https://doi.org/10.3129/i08-160 [published Online First: 2009/01/27]

15. Fan JC, Niederer RL, von Lany $\mathrm{H}$ et al (2008) Infectious endophthalmitis: clinical features, management and visual outcomes. Clin Exp Ophthalmol 36(7):631-636. https://doi.org/10.1111/j.1442-9071.2008.01813.x [published Online First: 2008/11/06]

16. Yang XB, Liu YY, Huang ZX et al (2018) Clinical Analysis of 1593 Patients with Infectious Endophthalmitis: A 12-Year Study at a Tertiary Referral Center in Western China. Chin Med J (Engl) 131 (14):1658-1665. https://doi. org/10.4103/0366-6999.235866 [published Online First: 2018/07/13]

17. Bhoomibunchoo C, Ratanapakorn T, Sinawat S et al (2013) Infectious endophthalmitis: review of 420 cases. Clin Ophthalmol 7:247-252. https:// doi.org/10.2147/OPTH.S39934 [published Online First: 2013/02/14]

18. Sharma S, Padhi TR, Basu S et al (2014) Endophthalmitis patients seen in a tertiary eye care centre in Odisha: a clinico-microbiological analysis. Indian J Med Res 139(1):91-98 [published Online First: 2014/03/08]

19. Ramakrishnan R, Bharathi MJ, Shivkumar C et al (2009) Microbiological profile of culture-proven cases of exogenous and endogenous endophthalmitis: a 10-year retrospective study. Eye (Lond) 23(4):945-956. https://doi.org/10.1038/eye.2008.197 [published Online First: 2008/07/05]

20. Benz MS, Scott IU, Flynn HW Jr et al (2004) Endophthalmitis isolates and antibiotic sensitivities: a 6-year review of culture-proven cases. Am J Ophthalmol 137(1):38-42. https://doi.org/10.1016/s0002-9394(03)00896-1 [published Online First: 2004/01/01]

21. Callegan MC, Engelbert M, Parke DW 2nd et al (2002) Bacterial endophthalmitis: epidemiology, therapeutics, and bacterium-host interactions. Clin Microbiol Rev 15(1):111-124. https://doi.org/10.1128/cmr. 15.1.111-124.2002 [published Online First: 2002/01/10]

22. Long C, Liu B, Xu C et al (2014) Causative organisms of post-traumatic endophthalmitis: a 20-year retrospective study. BMC Ophthalmol 14:34. https://doi.org/10.1186/1471-2415-14-34 [published Online First: 2014/03/26]

23. Chaudhry IA, Shamsi FA, Al-Harthi E et al (2008) Incidence and visual outcome of endophthalmitis associated with intraocular foreign bodies. Graefes Arch Clin Exp Ophthalmol 246(2):181-186. https://doi.org/10.1007/ s00417-007-0586-5 [published Online First: 2007/05/01]

24. Cornut PL, el Youssef B, Bron A et al (2013) A multicentre prospective study of post-traumatic endophthalmitis. Acta Ophthalmol 91(5):475-482. https://doi. org/10.1111/j.1755-3768.2011.02349.x [published Online First: 2012/02/09]

25. Sheu SJ (2017) Endophthalmitis. Korean J Ophthalmol 31(4):283-289. https://doi.org/10.3341/kjo.2017.0036 [published Online First: 2017/07/29]

26. Sadiq MA, Hassan M, Agarwal A et al (2015) Endogenous endophthalmitis: diagnosis, management, and prognosis. J Ophthalmic Inflamm Infect 5(1): 32. https://doi.org/10.1186/s12348-015-0063-y [published Online First: 2015/ $11 / 04]$

27. Sridhar J, Flynn HW Jr, Kuriyan AE et al (2013) Endogenous fungal endophthalmitis: risk factors, clinical features, and treatment outcomes in mold and yeast infections. J Ophthalmic Inflamm Infect 3, 60(1). https://doi. org/10.1186/1869-5760-3-60 [published Online First: 2013/09/24] 
28. Ness T, Pelz K, Hansen LL (2007) Endogenous endophthalmitis: microorganisms, disposition and prognosis. Acta Ophthalmol Scand 85(8): 852-856. https://doi.org/10.1111/j.1600-0420.2007.00982.x [published Online First: 2007/08/30]

29. Wong TY, Chee SP (2004) The epidemiology of acute endophthalmitis after cataract surgery in an Asian population. Ophthalmology 111(4):699-705. https://doi.org/10.1016/j.ophtha.2003.07.014 [published Online First: 2004/ 03/31]

30. Cao H, Zhang L, Li L et al (2013) Risk factors for acute endophthalmitis following cataract surgery: a systematic review and meta-analysis. PLoS One 8(8):e71731. https://doi.org/10.1371/journal.pone.0071731 [published Online First: 2013/08/31]

31. Ravindran RD, Venkatesh R, Chang DF et al (2009) Incidence of post-cataract endophthalmitis at Aravind Eye Hospital: outcomes of more than 42,000 consecutive cases using standardized sterilization and prophylaxis protocols. J Cataract Refract Surg 35(4):629-636. https://doi.org/10.1016/j.jcrs.2009.01. 002 [published Online First: 2009/03/24]

32. Lalitha P, Rajagopalan J, Prakash K et al (2005) Postcataract endophthalmitis in South India incidence and outcome. Ophthalmology 112(11):1884-1889. https://doi.org/10.1016/j.ophtha.2005.05.020 [published Online First: 2005/ 09/15]

33. Li J, Morlet N, Ng JQ et al (2004) Significant nonsurgical risk factors for endophthalmitis after cataract surgery: EPSWA fourth report. Invest Ophthalmol Vis Sci 45(5):1321-1328. https://doi.org/10.1167/iovs.03-1000 [published Online First: 2004/04/28]

34. Shirodkar AR, Pathengay A, Flynn HW Jr et al (2012) Delayed- versus acuteonset endophthalmitis after cataract surgery. Am J Ophthalmol 153(3):39198 e2. https://doi.org/10.1016/j.ajo.2011.08.029 [published Online First: 2011/ 10/28]

35. Maalouf F, Abdulaal M, Hamam RN (2012) Chronic postoperative endophthalmitis: a review of clinical characteristics, microbiology, treatment strategies, and outcomes. Int J Inflam 2012:313248. https://doi.org/10.1155/ 2012/313248 [published Online First: 2012/05/03]

36. Malihi M, Li X, Patel S et al (2017) Infectious keratitis-associated endophthalmitis: a 14-Year Study. Retina 37(4):662-666. https://doi.org/10. 1097/IAE.0000000000001204 [published Online First: 2016/07/19]

\section{Publisher's Note}

Springer Nature remains neutral with regard to jurisdictional claims in published maps and institutional affiliations.

\section{Submit your manuscript to a SpringerOpen ${ }^{\circ}$ journal and benefit from:}

- Convenient online submission

- Rigorous peer review

- Open access: articles freely available online

- High visibility within the field

- Retaining the copyright to your article

Submit your next manuscript at $\boldsymbol{\nabla}$ springeropen.com 